\title{
Patterns of Care of Gallbladder Cancer During the COVID-19 Pandemic: An Experience of Tertiary Care Centre at Patna, India
}

\author{
Dharmendra Singh, Pritanjali Singh, Avik Mandal, Amrita Rakesh, Manika \\ Verma
}

Department of Radiotherapy, All India Institute of Medical Sciences, Patna, India.

\begin{abstract}
Introduction: The novel coronavirus disease 2019 (COVID-19), is caused by the severe acute respiratory syndrome cronavirus 2 (SARS-CoV2). The management of cancer patients is very challenging during the COVID-19 pandemic. Cancer itself as well as anticancer treatment leads to compromised immunity of patients with increased risk of infection. This is turn leads to increased hospital visits. It forms a vicious cycle that increases the risk of COVID-19 susceptibility to cancer patients. Patients on anticancer treatment alongwith COVID-19 infection have higher risk of morbidity and mortality. Aim: To compare the epidemiological characteristics and management decisions in gallbladder cancer patients during COVID-19 pandemic. Methods: This retrospective study was conducted at All India Institute of Medical Sciences (AIIMS), Patna. Patients were divided into two group pre-COVID (patients attending radiotherapy department from December 2019 to February 2020) and established-COVID group patients (patients attending radiotherapy department from March 2020 to May 2020) with histopathological confirmed diagnosis of gallbladder cancer. Results: Histopathological confirmed cases of gallbladder cancer $(\mathrm{n}=85)$ were analyzed, 56 patients from pre-COVID timeline and 29 patients from established-COVID timeline were selected. During the pre-COVID timeline, $55.4 \%$ of the patients directly visited the radiotherapy department while, $24.1 \%$ patients directly attended the radiotherapy department during the established-COVID time. This reduction of number of patients at radiotherapy department was statistically significant $(\mathrm{p}=0.006)$. There was statistically significant reduction $(\mathrm{p}=0.014)$ in number of patients attending from rural areas during established-COVID time. Chemotherapy regimen used during pre-COVID and establishedCOVID timeline was significantly $(\mathrm{p}<0.001)$ different. Conclusion: Cancer patient management during COVID-19 pandemic is an important issue. Chemotherapy increases the risk of COVID-19 infection by reducing the immunity. Single agent oral capecitabine is a good option for patients of gallbladder cancer in the adjuvant or palliative settings with less toxicity and requiring less hospital visits compared to intravenous chemotherapy.
\end{abstract}

Keywords: COVID-19- gallbladder cancer and COVID pandemic- India

Asian Pac J Cancer Care, 5 (Suppl 1), 51-57

\section{Introduction}

The novel coronavirus disease 2019 (COVID-19) is caused by the severe acute respiratory syndrome cronavirus 2 (SARS-CoV2). COVID-19 was declared as a pandemic on 11th March 2020 by the World Health Organization (WHO) [1-2]. The COVID-19 pandemic is on the rise and has reached most parts of the world. The increase in number of cases had a significant impact
Submission Date: 06/26/2020 Acceptance Date: 07/27/2020

\footnotetext{
Corresponding Author:

Dr. Dharmendra Singh

Department of Radiotherapy, All India Institute of Medical Sciences, Patna, India.

Email: babu.dsingh.singh35@gmail.com
}

on the health care resources. The resources of health care management are diverted towards prevention and management of COVID-19 cases in terms of intensive care units, ventilators, health care workers and others resources [3]. All over the world, "lockdown" or "social distancing" has been considered the most effective method to control the outbreak of COVID-19 [4]. Due to the high infectivity 
rate and rapid increase in number of cases affected with COVID-19, most of health care institutes or hospitals have reduced or stopped the elective interventions. Cancer management is always a multidisciplinary approach, hence suggested to be well planned with discussion regarding type of intervention and expected outcome. Cancer treatment is considered as nonemergency [5], however patients cannot persistently wait to start therapy. The National Cancer Registry Programme of India showed 14.6 cancer cases per lakh population [6]. Cancer care is resource consuming and requires social and moral support for the patients. In the current COVID-19 pandemic there is no evidence based guidelines for the management of cancer patients. Gallbladder cancer is associated with advanced stage at presentation and poor outcome in view of its nonspecific symptoms. It is also highly prevalent in the Gangetic plains of India [7]. Treatment consists of surgery followed by adjuvant chemotherapy or radiation for early operable cases [8]. However, most of our patients present late where only palliative chemotherapy or best supportive care can be offered. There are concerns regarding the administration of systemic chemotherapeutic agents in cancer patients during this pandemic. The systemic chemotherapeutic agents make the patients susceptible to COVID-19 infection due to immunosuppression [9]. Patients with cancer who have COVID-19 infection have a higher risk of mortality and complications [10]. In the absence of evidence-based guidelines, there is a dilemma about whether to administer systemic chemotherapy. We conducted retrospective analysis to assess the epidemiology and patterns of care in gallbladder cancer patients during the pandemic.

\section{Materials and Methods}

\section{General methodology}

A retrospective analysis was performed in the department of radiotherapy at All India Institute of Medical Sciences (AIIMS), Patna, a tertiary care center in Bihar, India. The data were obtained from departmental records. From $1^{\text {st }}$ December 2019 to $31^{\text {st }}$ May 2020.

\section{Patient selection}

Patients histopathologically diagnosed with gallbladder cancer attending radiotherapy department from December 2019 to May 2020, were selected for analysis. The patients were divided into two-group pre-COVID and established-COVID There was no clear demarcation between these two groups. First case of COVID-19 was confirmed in India on 30 January 2020. By the end of February 2020, only two confirmed cases of COVID-19 were seen in India. Therefore, patients attending radiotherapy department from December 2019 to February 2020 were included in pre-COVID group and form March 2020 to May 2020 included in established-COVID group. First case of COVID-19 was confirmed, in Bihar from Munger district on 22 March 2020. There was steady rise of COVID-19 cases since then in Bihar. The adjuvant or palliative chemotherapy commonly advised at AIIMS, Patna for gallbladder cancer includes injection Gemcitabine $1000 \mathrm{mg} / \mathrm{m}^{2}$ day 1,8 and Oxaliplatin $80 \mathrm{mg} / \mathrm{m}^{2}$ day 1,8 with 3 weekly cycles (Gem/Ox) regimen. Those patients started on Gem/Ox regimen during pre-COVID time were considered for same Gem/Ox regimen during the established-COVID time but the day 8 was omitted to reduce the number of hospital visits. Patient diagnosed with gallbladder cancer during the established-COVID, having an indication of adjuvant or palliative chemotherapy were considered for any of the following chemotherapy regimen: Gem/ Ox or single agent oral capecitabine $1000 \mathrm{mg} / \mathrm{m}^{2}$ orally day 1 to day 14, three weekly (Cap) regimen or injection gemcitabine $1000 \mathrm{mg} / \mathrm{m}^{2}$ day 1,8 and tablet capecitabine $825 \mathrm{mg} / \mathrm{m}^{2}$ orally day 1 to day 14 , three weekly cycle (Gem/Cap) regimen. Again, to reduce the hospital visit and chemotherapy related toxicities day 8 of Gem/Ox or Gem/Cap regimen was omitted. Patients whose general condition did not permit were given best supportive care.

Treatment of any kind to the patient provides psychological benefit to them whatever is the stage of the disease. Best supportive care includes the adequate pain relief with analgesics, management of toxicities, and the care of nutritional needs. While providing best supportive care to patients the caregivers or attendants were sensitized, regarding less hospital visit during the established-COVID pandemic and encouraged for the use of telemedicine facility of AIIMS, Patna.

\section{Data collection}

Retrospectively data was retrieved from recorded files from the department of radiotherapy. Data was collected with respect to age, gender, referred cases from other department or first visit, address (district), distance from Patna, rural or urban residence, Eastern Cooperative Oncology Group Performance Status (ECOG PS), stage, surgery, and management decision.

\section{Data analysis}

The data were analyzed using the Statistical Package for the Social Science (SPSS version 25, IBM Corp). Two sided Chi-square test with $\mathrm{p}=0.05$ or less was considered statistically significant.

\section{Results}

\section{The COVID time}

Eighty five $(n=85)$ patients of histopathologically confirmed gallbladder cancer were analyzed who attended the radiotherapy department of AIIMS, Patna from December 2019 to May 2020. The number of patients in pre-COVID and established-COVID periods were 56 and 29 respectively.

\section{Epidemiological characteristics}

Patients attending radiotherapy department were divided into two groups, new cases who directly visit radiotherapy outpatient for consultation and patients who attends radiotherapy department with referral from other departments. During the pre-COVID timeline, $55.4 \%$ of the patients directly visited the radiotherapy department while 
Table 1. Epidemiological and Clinical Characteristics of the Patients

\begin{tabular}{|c|c|c|c|c|c|c|}
\hline & & \multicolumn{4}{|c|}{ Peri-COVID time } & \multirow{3}{*}{$\mathrm{p}$ - value } \\
\hline & & \multicolumn{2}{|c|}{ Pre-COVID } & \multicolumn{2}{|c|}{ Established-COVID } & \\
\hline & & $\mathrm{N}=56$ & Table N (\%) & $\mathrm{N}=29$ & Table N (\%) & \\
\hline \multirow[t]{2}{*}{ Type of case } & New & 31 & 55.40 & 7 & 24.10 & \multirow[t]{2}{*}{0.006} \\
\hline & Referral & 25 & 44.60 & 22 & 75.90 & \\
\hline \multirow[t]{6}{*}{ Age group } & Upto 30 years & 0 & 0.00 & 2 & 6.90 & \multirow{6}{*}{0.097} \\
\hline & $30-40$ years & 10 & 17.90 & 1 & 3.40 & \\
\hline & $41-50$ years & 17 & 30.40 & 11 & 37.90 & \\
\hline & $51-60$ years & 13 & 23.20 & 6 & 20.70 & \\
\hline & $61-70$ years & 13 & 23.20 & 9 & 31.00 & \\
\hline & $>70$ years & 3 & 5.40 & 0 & 0.00 & \\
\hline \multirow[t]{2}{*}{ Gender } & Male & 24 & 42.90 & 6 & 20.70 & \multirow[t]{2}{*}{0.043} \\
\hline & Female & 32 & 57.10 & 23 & 79.30 & \\
\hline \multirow[t]{6}{*}{ Distance group } & $<50 \mathrm{~km}$ & 21 & 37.50 & 10 & 34.50 & \multirow{6}{*}{0.891} \\
\hline & $51-100 \mathrm{~km}$ & 13 & 23.20 & 9 & 31.00 & \\
\hline & $101-150 \mathrm{~km}$ & 16 & 28.60 & 8 & 27.60 & \\
\hline & $151-200 \mathrm{~km}$ & 5 & 8.90 & 2 & 6.90 & \\
\hline & $201-250 \mathrm{~km}$ & 0 & 0.00 & 0 & 0.00 & \\
\hline & $>251 \mathrm{~km}$ & 1 & 1.80 & 0 & 0.00 & \\
\hline \multirow[t]{2}{*}{ Rural/urban } & Rural & 29 & 51.80 & 7 & 24.10 & \multirow[t]{2}{*}{0.014} \\
\hline & Urban & 27 & 48.20 & 22 & 75.90 & \\
\hline \multirow[t]{5}{*}{ ECOG } & ECOG 0 & 7 & 12.50 & 0 & 0.00 & \multirow{5}{*}{0.288} \\
\hline & ECOG 1 & 6 & 10.70 & 3 & 10.30 & \\
\hline & ECOG 2 & 16 & 28.60 & 9 & 31.00 & \\
\hline & ECOG 3 & 17 & 30.40 & 13 & 44.80 & \\
\hline & ECOG 4 & 10 & 17.90 & 4 & 13.80 & \\
\hline \multirow[t]{2}{*}{ Jaundice } & Yes & 20 & 35.70 & 7 & 24.10 & \multirow[t]{2}{*}{0.277} \\
\hline & No & 36 & 64.30 & 22 & 75.90 & \\
\hline \multirow[t]{4}{*}{ Stage } & Stage 1 & 0 & 0.00 & 0 & 0.00 & \multirow{4}{*}{0.427} \\
\hline & Stage 2 & 2 & 3.60 & 3 & 10.30 & \\
\hline & Stage 3 & 10 & 17.90 & 4 & 13.80 & \\
\hline & Stage 4 & 44 & 78.60 & 22 & 75.90 & \\
\hline \multirow[t]{2}{*}{ Metastasis } & Yes & 44 & 78.60 & 22 & 75.90 & \multirow[t]{2}{*}{0.776} \\
\hline & No & 12 & 21.40 & 7 & 24.10 & \\
\hline \multirow[t]{2}{*}{ Surgery } & Yes & 12 & 21.40 & 6 & 20.70 & \multirow[t]{2}{*}{0.937} \\
\hline & No & 44 & 78.60 & 23 & 79.30 & \\
\hline Management & Adjuvant & 12 & 21.40 & 6 & 20.70 & \\
\hline & Palliative & 34 & 60.70 & 16 & 55.20 & 0.786 \\
\hline & Best supportive care & 10 & 17.90 & 7 & 24.10 & \\
\hline Regimen & No chemotherapy & 10 & 17.90 & 7 & 24.10 & \\
\hline & Capecitabine & 0 & 0.00 & 11 & 37.90 & $<0 \Omega 01$ \\
\hline & $\mathrm{Gem} / \mathrm{Ox}$ & 46 & 82.10 & 5 & 17.20 & -0.001 \\
\hline & Gem / CAP & 0 & 0.00 & 6 & 20.70 & \\
\hline
\end{tabular}

ECOG- Eastern Cooperative Oncology Group; CAP- capecitabine; Gem- gemcitabine; Ox- Oxaliplatin; km- kilometer; COVID- novel coronavirus disease

$44.6 \%$ patients were referred from other departments. During the established-COVID time, $24.1 \%$ patients directly attended the radiotherapy department and $75.9 \%$ patients were referred from other departments. The change in patients referral was statistically significant $(p=0.006)$.
The distribution of the patient was analyzed according to the district from where they belong during pre-COVID and established-COVID time and is shown in Figure 1a and $1 \mathrm{~b}$. The male and female patients were $42.9 \%$ and $44.6 \%$ respectively in pre-COVID timeline. The male 


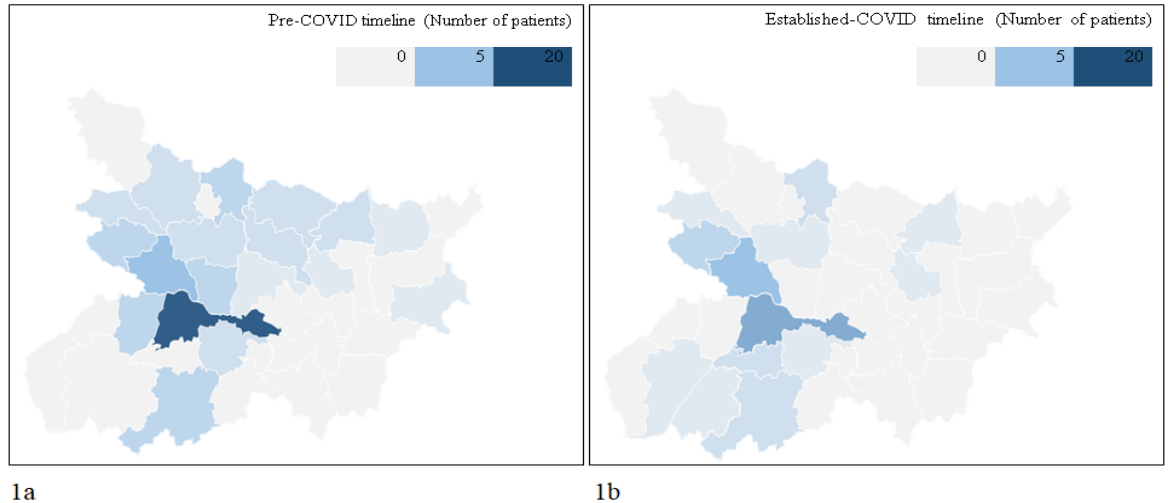

Figure 1. 1a, Distribution of Patients According to Residential Districts of Bihar During pre-COVID Timeline. 1b, Distribution of Patients According to Residential Districts of Bihar During Established-COVID Timeline.

and female patients were $20.7 \%$ and $79.3 \%$ respectively in established-COVID timeline. The gender-wise distribution of patient were differing while comparing them with pre-COVID and established-COVID, these differences were statistically significant $(\mathrm{p}=0.043)$. The median age of patient was 53 years and the most common age group of patients was 41-50 years in both pre and established-COVID. The distribution of patient according to age group shown in Figure 2. During pre-COVID time $35.7 \%$ of patients presented with jaundice and during established-COVID $24.1 \%$ presented with jaundice. The median value of CA19.9 was $327 \mathrm{U} /$ $\mathrm{ml}$ and $254 \mathrm{U} / \mathrm{ml}$ in pre-COVID and established-COVID time respectively. The patients from rural area were $51.8 \%$ and $24.1 \%$ in pre-COVID and established-COVID timeline respectively and the difference was statistically significant $(\mathrm{p}=0.014)$. Distribution of patient according to the area of residence depicted in Figure 3. ECOG PS at presentation was ECOG 3 in both pre-COVID (30.4\%) and established-COVID (44.8\%). Stage 4 was the most common stage at presentation. $78.6 \%$ and $75.9 \%$ of patients presented with metastasis during pre and established-COVID respectively. In pre-COVID timeline adjuvant chemotherapy, palliative chemotherapy, and best supportive care was considered in $21.4 \%, 60.7 \%$, and $17.9 \%$ respectively. During established-COVID timeline

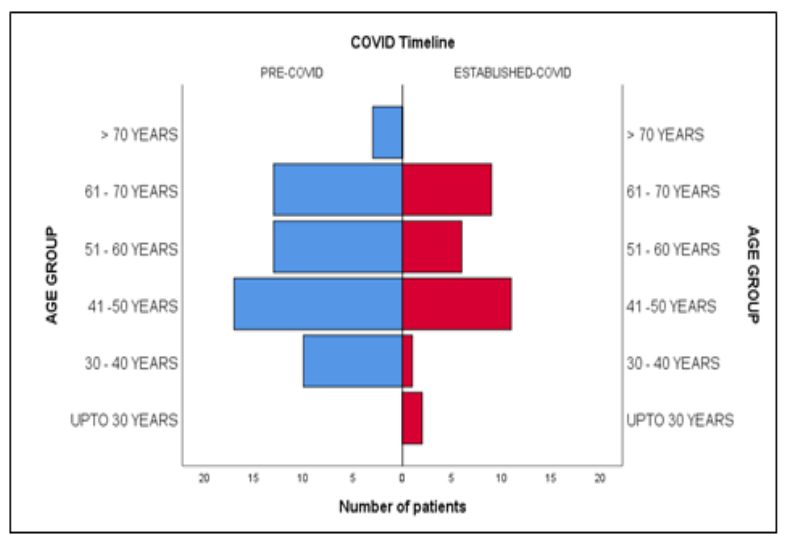

Figure 2. Distribution of Patients During Pre and Established COVID According to Age Group adjuvant chemotherapy, palliative chemotherapy, and best supportive care was considered in $20.7 \%, 55.2 \%$, and $24.1 \%$ respectively. Patterns of management was not statistically significant $(p=0.786)$. In pre-COVID timeline best supportive care was advised in $17.9 \%$ of patients, $21.7 \%$ adjuvant intravenous chemotherapy and $60.4 \%$ palliative chemotherapy while $24.1 \%$ received best supportive care, $37.9 \%$ adjuvant or palliative oral chemotherapy, and $37.9 \%$ received adjuvant or palliative intravenous chemotherapy in established-COVID. This difference in regimen of chemotherapy was statistically significant $(\mathrm{p}<0.001)$. The baseline epidemiological characteristics are shown in Table 1.

\section{Patient care}

\section{Treatment intent}

Out of 56 patients in pre-COVID group, 12 (21.4\%) patients underwent surgical intervention and were planned for adjuvant treatment in form of systemic chemotherapy alone or chemotherapy and radiotherapy. Palliative systemic chemotherapy $\mathrm{Gem} / \mathrm{Ox}$ was considered in $34(60.7 \%)$ patients. Best supportive care advised in $10(17.9 \%)$ patients. In established-COVID group, out of 29 patients $6(20.7 \%)$ patients underwent surgical intervention and considered for adjuvant chemotherapy (Gem/Ox or Gem/Cap or Cap alone). Only one patient was enrolled for neoadjuvant chemotherapy (Gem/Ox) followed by surgical assessment. $16(55.2 \%)$ patients out of 22 who presented with metastatic disease were considered for palliative chemotherapy and 7 (24.1\%) advised for best supportive care. Adjuvant and palliative chemotherapy was advised in 6 (20.7\%) and 16 (55.2\%) respectively. Best supportive care was considered in 7 $(24.1 \%)$ patients. To reduce the hospital visit in view of COVID-19 pandemic day 8 of the regimens were omitted.

\section{Chemotherapy}

Adjuvant and palliative chemotherapy in pre-COVID group was consisted $\mathrm{Gem} / \mathrm{Ox}$, which was considered in $82.1 \%$ of patients including adjuvant $(21.4 \%)$ and palliative $(60.7 \%)$ intent. In established-COVID group, adjuvant and palliative chemotherapy regimen used were 


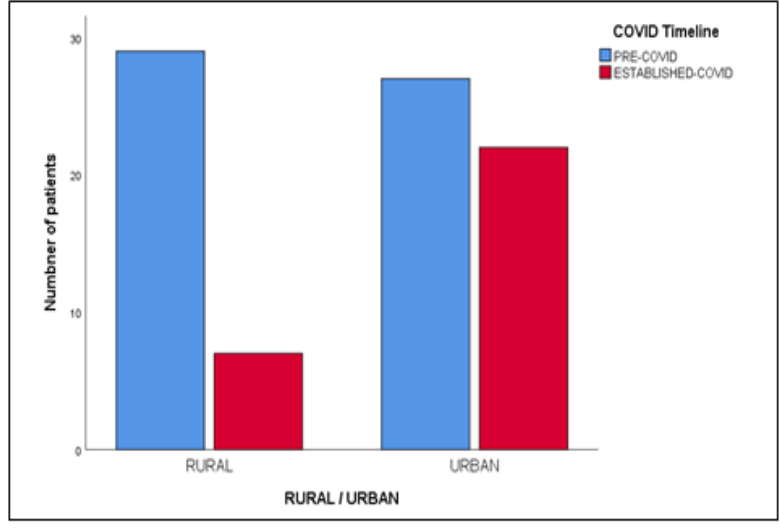

Figure 3. Distribution of Patients During Pre and Established-COVID According to Area of Residence (rural or urban)

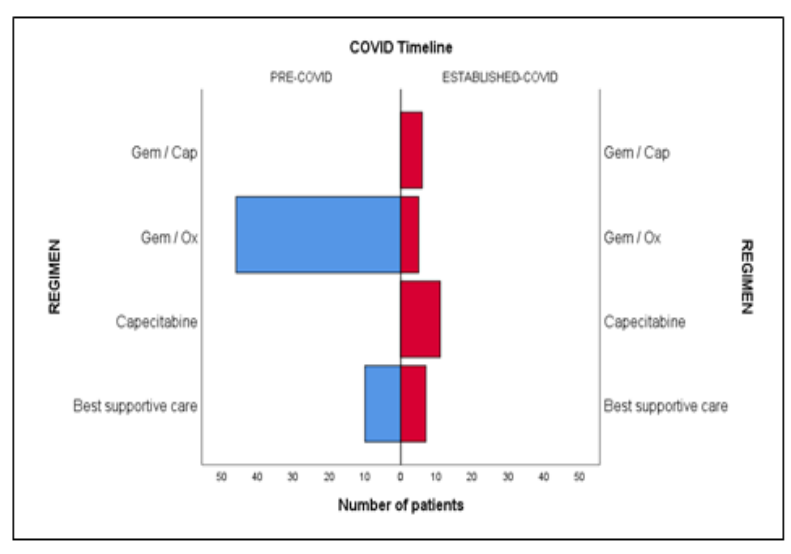

Figure 4. Distribution of Patients During Pre and Established COVID Received Different Types of Chemotherapy Regimens

as Gem/Ox, Gem/Cap, and Cap only. Gem/Ox, Gem/ Cap, and Cap was advised in $17.2 \%, 20.7 \%$, and $37.9 \%$ respectively depending on the ECOG PS, stage, and distance from health care facility. Distribution of patients according to chemotherapy regimen advised is depicted in Figure 4 . There was statistically significant difference in the selection of chemotherapy regimen during pre-COVID and established-COVID time $(\mathrm{p}<0.001)$.

\section{Best supportive care}

Best supportive care was advised to the patients according to the stage, ECOG PS, health care access facility, and severity of the symptoms. WHO ladder of pain control was followed for pain management. Adequate pain relief with analgesics, management of toxicities, and the care of nutritional needs were remained the integral part best supportive care. Best supportive care was 17.9\% and $24.1 \%$ during pre-COVID and established-COVID timeline. This increase in number of patient for best supportive care was not statistically significant $(p=0.786)$.

\section{Discussion}

Gallbladder cancer is one of the most common malignancies in this part of the world. The majority of the gallbladder cancer patients presents in an advanced stage with poor prognosis. The medial survival of gallbladder cancer patients is around 6 months [11]. A study by Liang $\mathrm{W}$ et al. suggested that cancer patients with COVID-19 infection undergoing treatment have a higher morbidity and mortality [12]. The health care system is already burdened during the COVID-19 pandemic due to resource mobilization towards management of COVID-19 cases. Cancer patients planned for intravenous (IV) systemic chemotherapy are at higher risk of hospital acquired COVID-19 infection due to frequent hospital visits. There is significant reduction in the number of patients attending health care facility during the established-COVID time. In this study, there is $48.21 \%$ reduction in the number of gallbladder cancer patients in established-COVID time as compared to pre-COVID time. There was significant reduction in number of patients with gallbladder cancer, especially the patients who directly attended the radiotherapy department in established-COVID timeline. We found that the main proportion of the patients $(75.9 \%)$ with gallbladder cancer were actually referred from different departments during the established-COVID timeline, while in pre-COVID time the referral cases from other departments were $44.6 \%$. The most common age group at presentation remains same $41-50$ years. $37.5 \%$ of patients were within a range of $<50$ kilometer (KM) of distance from AIIMS, Patna in pre-COVID time. In established-COVID time, $34.5 \%$ of patients were from distance within $<50 \mathrm{KM}$. Before the established-COVID time the most of the patients were attending from the rural areas $(51.8 \%)$ while during the established-COVID time most of the patients attending AIIMS, Patna were from urban areas $(75.9 \%)$. This may be due to the lockdown started by Government of India on 24th of March 2020 and inadequate access of mode of transport or other resources. In this study, the clinical presentation of patients while comparing the pre-COVID and established-COVID remains similar with respect to jaundice, stage, and surgical resectability. In this study, $30.4 \%$ of patients presented with ECOG 3 in pre-COVID time and $44.8 \%$ of patients presented with ECOG 3 at established-COVID time. This increase in percentage of patients of gallbladder cancer with poor ECOG may be due to inadequate transportation availability and strict enforcement of lockdown rules. Most of them were planned for palliative single agent capecitabine. The advantage of oral capecitabine is being in terms of ease of administration, less toxic, taken at home in isolated setting, and requiring less hospital visits while comparing to other systemic intravenous chemotherapy. Patt YZ et al. demonstrated the advantage of single agent capecitabine in adjuvant setting over Gem/Ox, but the numbers of patients were very small in their study [13]. Postoperative case of gallbladder cancer that had an indication of adjuvant treatment, adjuvant treatment was advised generally in the form of intravenous systemic chemotherapy with or without adjuvant radiation. During 
the pre-COVID time, Gem/Ox was the most commonly advised adjuvant chemotherapy at our institute. During the established-COVID time the patients had an indication of adjuvant chemotherapy were also considered for Gem/ Ox, but day 8 chemotherapy was omitted. Single agent oral Capecitabine is also an option for patients requiring adjuvant chemotherapy as per American Society of Clinical Oncology [14]. In this study, $37.9 \%$ of patients were advised for single agent capecitabine either as an adjuvant or palliative chemotherapy due to ease of its administration and need of less frequent visit with manageable toxicity during the established-COVID time. BILCAP trial showed the advantage of gemcitabine over observation only in per-protocol analysis [15]. In this study, patients advised for best supportive care were $17.9 \%$ and $24.1 \%$ during pre-COVID and established-COVID timeline. This increase in number of patient for best supportive care was not statistically significant $(p=0.786)$. Best supportive care included adequate pain relief with analgesics, management of toxicities, optimal nutritional care. To reduce the number of hospital visits telemedicine facility were utilized. Recent publication by Patel A et al. recommended oral capecitabine as an adjuvant chemotherapy with ECOG 0,1 and 2. While considering the palliative chemotherapy only tablet capecitabine or tablet erlotinib was recommended for ECOG 0 and 1. Best supportive care was recommended for ECOG 2, 3 and 4 [16].

In conclusion, gallbladder cancer is a significant public health care problem in this part of the world. Most of the patients presents at an advanced stage. COVID-19 pandemic had created a dilemma among the oncologists, how to manage cancer patients during the COVID-19 pandemic. Systemic chemotherapy increases the risk of morbidity and mortality during active COVID-19 infection. Systemic intravenous chemotherapy further increases the risk of complication in cancer patients. While considering the optimal treatment for the gallbladder cancer the aim should be to balance the risk, benefit of the patient, and health care providers and at the same time considering minimum constraint to the existing health care system. Gallbladder cancer patients may be considered for oral single agent chemotherapy instead of intravenous chemotherapy during this COVID-19 pandemic in presence of preserved ECOG performance status and appropriate indication.

\section{Acknowledgments}

We acknowledge the help extended by the Department of Surgical Oncology, All India Institute of Medical Sciences, Patna.

\section{Financial support and sponsorship} Nil

\section{Conflicts of Interest}

The authors have no conflicts of interest to declare.

\section{References}

1. del Rio C, Malani PN. COVID-19-New Insights on a Rapidly Changing Epidemic. JAMA. 202004 14;323(14):1339. https://doi.org/10.1001/jama.2020.3072

2. WHO (World Health Organization). Statement on the Meeting of the International Health Regulations (2005) Emergency Committee Regarding the Outbreak of Novel Coronavirus (2019-nCoV). Geneva, Switzerland: WHO Newsletter; 2020. https://www.who.int/newsroom/detail/ 23-01-2020-statement-on-the-meeting-ofthe-internationalhealth-regulations-(2005)-emergencycommittee-regardingthe-outbreak-of-novel-coronavirus(2019-ncov).

3. Pfeiffer S U. Hospitals Prepare Guidelines For Who gets Care Amid Coronavirus Surge. NPR. Available from: https://www.npr.org/2020/03/21/819645036/u-s-hospitaalsprepare-guidelines-for-who-gets-care-amid-coronavirussurge.

4. MacIntyre CR, Wang Q. Physical distancing, face masks, and eye protection for prevention of COVID-19. The Lancet. 2020 06;395(10242):1950-1951. https://doi.org/10.1016/ s0140-6736(20)31183-1

5. De Felice F, Tombolini V, de Vincentiis M, Magliulo G, Greco A, Valentini V, Polimeni A. Multidisciplinary team in head and neck cancer: a management model. Medical Oncology. 2018 Nov 13;36(1). https://doi.org/10.1007/ s12032-018-1227-z

6. National Cancer Registry Programme, Consolidated reports of the population based cancer registries 1990-96. Indian Council of Medical Research, New Delhi, India: 2001.

7. Pandey A, Madhawi R, Raj S, Mandal M, Devi S, Sinha P, Singh R. Geographical pattern of carcinoma gallbladder in Bihar and its association with river Ganges and arsenic levels: Retrospective individual consecutive patient data from Regional Cancer Centre. South Asian Journal of Cancer. 2018;7(3):167. https://doi.org/10.4103/sajc. sajc_37_18

8. Zhu AX, Hong TS, Hezel AF, Kooby DA. Current Management of Gallbladder Carcinoma. The Oncologist. 2010 02;15(2):168-181. https://doi.org/10.1634/ theoncologist.2009-0302

9. Yeoh CB, Lee KJ, Rieth EF, Mapes R, Tchoudovskaia AV, Fischer GW, Tollinche LE. COVID-19 in the Cancer Patient. Anesthesia \& Analgesia. 202004 15;131(1):16-23. https:// doi.org/10.1213/ane.0000000000004884

10. Liang W, Guan W, Chen R, Wang W, Li J, Xu K, Li C, Ai Q, Lu W, Liang H, Li S, He J. Cancer patients in SARSCoV-2 infection: a nationwide analysis in China. The Lancet Oncology. 2020 03;21(3):335-337. https://doi.org/10.1016/ s1470-2045(20)30096-6

11. Pandey A, Raj S, Madhawi R, Devi S, Singh R. Cancer trends in Eastern India: Retrospective hospital-based cancer registry data analysis. South Asian Journal of Cancer. 2019;8(4):215. https://doi.org/10.4103/sajc.sajc_321_18

12. Liang W, Guan W, Chen R, Wang W, Li J, Xu K, Li C, Ai $\mathrm{Q}, \mathrm{Lu} \mathrm{W}$, Liang H, Li S, He J. Cancer patients in SARSCoV-2 infection: a nationwide analysis in China. The Lancet Oncology. 2020 03;21(3):335-337. https://doi.org/10.1016/ s1470-2045(20)30096-6

13. Patt YZ, Hassan MM, Aguayo A, Nooka AK, Lozano RD, Curley SA, Vauthey J, Ellis LM, Schnirer II, Wolff RA, Charnsangavej C, Brown TD. Oral capecitabine for the treatment of hepatocellular carcinoma, cholangiocarcinoma, and gallbladder carcinoma. Cancer. 200407 19;101(3):578586. https://doi.org/10.1002/cncr.20368

14. Shroff RT, Kennedy EB, Bachini M, Bekaii-Saab T, 
Crane C, Edeline J, El-Khoueiry A, Feng M, Katz MH, Primrose J, Soares HP, Valle J, Maithel SK. Adjuvant Therapy for Resected Biliary Tract Cancer: ASCO Clinical Practice Guideline. Journal of Clinical Oncology. 201904 20;37(12):1015-1027. https://doi.org/10.1200/jco.18.02178

15. Primrose JN, Fox RP, Palmer DH, Malik HZ, Prasad R, Mirza D, Anthony A, Corrie P, Falk S, Finch-Jones M, Wasan H, Ross P, Wall L, Wadsley J, Evans JTR, Stocken D, Praseedom R, Ma YT, Davidson B, Neoptolemos JP, Iveson T, Raftery J, Zhu S, Cunningham D, Garden OJ, Stubbs C, Valle JW, Bridgewater J, Primrose J, Fox R, Morement H, Chan O, Rees C, Ma Y, Hickish T, Falk S, Finch-Jones M, Pope I, Corrie P, Crosby T, Sothi S, Sharkland K, Adamson D, Wall L, Evans J, Dent J, Hombaiah U, Iwuji C, Anthoney A, Bridgewater J, Cunningham D, Gillmore R, Ross P, Slater S, Wasan H, Waters J, Valle J, Palmer D, Malik H, Neoptolemos J, Faluyi O, Sumpter K, Dernedde U, Maduhusudan S, Cogill G, Archer C, Iveson T, Wadsley J, Darby S, Peterson M, Mukhtar A, Thorpe J, Bateman A, Tsang D, Cummins S, Nolan L, Beaumont E, Prasad R, Mirza D, Stocken D, Praseedom R, Davidson B, Raftery J, Zhu S, Garden J, Stubbs C, Coxon F. Capecitabine compared with observation in resected biliary tract cancer (BILCAP): a randomised, controlled, multicentre, phase 3 study. The Lancet Oncology. 2019 05;20(5):663-673. https://doi. org/10.1016/s1470-2045(18)30915-x

16. Patel A, Batra A, Mehta P, Sharma A, Sirohi B, Biswas B, et al. Gallbladder cancer: Adjuvant and palliative treatment during Covid-19 pandemic in India. Indian J Med Paediatr Oncol. 2020;41:132-4.

\section{(c) (i) (8)}

This work is licensed under a Creative Commons AttributionNon Commercial 4.0 International License. 